\title{
CAMA
}

Centre for Applied Macroeconomic Analysis

\section{Measuring exchange rate risks during periods of uncertainty}

\section{CAMA Working Paper 60/2020 June 2020}

\section{Laurent Ferrara}

Skema Business School, EconomiX - University Paris Nanterre

Centre for Applied Macroeconomic Analysis, ANU

\section{Joseph Yapi}

EconomiX - University Paris Nanterre

Centre for Applied Macroeconomic Analysis, ANU

\begin{abstract}
In this paper, we empirically look at the effects of uncertainty on risk measures for exchange rates, by focusing on two recent specific periods: the Brexit and the outbreak of the Covid-19. Based on a Fama regression extended with uncertainty measures, we forecast exchange rate in the short run through a quantile regression approach. By fitting a Skewed-Student distribution to the quantile forecasts, we put forward measures of risks for appreciation and depreciation of the expected exchange rates. We point out two interesting results. First, we show that the increase in Brexit-related uncertainty is strongly associated to higher future depreciation risks of the British Pound vs the Euro, as a mistrust towards the British economy. Second, we get that the Covid-related uncertainty is perceived as a global risk, leading to a flight-to-safety move towards the US Dollar and associated high depreciation risks for emerging currencies.
\end{abstract}




\title{
Keywords
}

Exchange rate, Risk measures, Fama regression, Uncertainty, Covid-19 crisis, Brexit

\author{
JEL Classification
}

C22, C53, F31

\section{Address for correspondence:}

(E) cama.admin@anu.edu.au

ISSN 2206-0332

The Centre for Applied Macroeconomic Analysis in the Crawford School of Public Policy has been established to build strong links between professional macroeconomists. It provides a forum for quality macroeconomic research and discussion of policy issues between academia, government and the private sector.

The Crawford School of Public Policy is the Australian National University's public policy school, serving and influencing Australia, Asia and the Pacific through advanced policy research, graduate and executive education, and policy impact. 


\title{
Measuring exchange rate risks during periods of uncertainty *
}

\author{
Laurent FERRARA Joseph YAPI $^{\ddagger}$
}

May 28, 2020

\begin{abstract}
In this paper, we empirically look at the effects of uncertainty on risk measures for exchange rates, by focusing on two recent specific periods: the Brexit and the outbreak of the Covid-19. Based on a Fama regression extended with uncertainty measures, we forecast exchange rate in the short run through a quantile regression approach. By fitting a Skewed-Student distribution to the quantile forecasts, we put forward measures of risks for appreciation and depreciation of the expected exchange rates. We point out two interesting results. First, we show that the increase in Brexit-related uncertainty is strongly associated to higher future depreciation risks of the British Pound vs the Euro, as a mistrust towards the British economy. Second, we get that the Covid-related uncertainty is perceived as a global risk, leading to a flight-to-safety move towards the US Dollar and associated high depreciation risks for emerging currencies.
\end{abstract}

Keywords: Exchange rate, Risk measures, Fama regression, Uncertainty, Covid-19 crisis, Brexit

JEL Codes: C22, C53, F31

\footnotetext{
${ }^{*}$ We would like to thank Menzie Chinn and Valérie Mignon for helpful comments.

†Skema Business School, EconomiX - University Paris Nanterre and CAMA - Australian National University, email: laurent.ferrara@skema.edu

${ }^{\ddagger}$ EconomiX - University Paris Nanterre, France, email: yapi.aj@parisnanterre.fr
} 


\section{Introduction}

On 23 June 2016, the outcome of the British referendum came as a surprise as prediction markets and polls suggested the vote would be in favor of remaining in the European Union. Until 31 January 2020, no decisive action was taken, leaving the U.K. economy, and the rest of the world connected to the U.K., with a large uncertainty. Many research papers have shown that this political uncertainty generated various adverse macroeconomic effects on the British economy, in line with the theory on uncertainty initiated by Knight (1921) and recently popularized by Bloom (2009). Negative domestic effects of the Brexit have been shown on U.K firms (Bloom et al. 2019), on trade (Born et al., 2019) or on household income (Dringhra et al., 2016). The main channel of transmission is the wait-and-see attitude of agents facing higher uncertainty, as well as increasing financial frictions. In principle, as soon as uncertainty fades, the economy experiences a bounce-back accompanying the business cycle. A major issue related to the Brexit case is that the uncertainty period lasted for several months in a row, generating more complex transmission mechanisms to economic and financial sectors. Although the euro area is likely to be one of the most affected economic zone by the Brexit uncertainty, worldwide effects are also non-negligible in some exposed countries (see Hassan et al., 2019). However, immediately after the Brexit shock, the first macroeconomic adjustment took place through the exchange rate. Indeed, between May 2015 (the date of the Conservatives' victory in the general elections, whose program included the holding of the referendum) and July 2017, the sterling depreciated in real terms by about 15\%. As pointed out by Gourinchas and Hale (2017) this drop reflects beliefs from market participants that the Brexit is expected to permanently affect the UK economic growth through reversal from trade gains between European partners and reduced cross-border labor flows, both factors weighing on potential growth.

More recently the Covid-19 pandemic, that started in China end of 2019², generated a worldwide recession during the first months of 2020, the U.S. and Western Europe being so far the most impacted as regards both public health and economic consequences (the peak in U.S. business cycle is likely to be in

\footnotetext{
${ }^{1}$ The first reported death from the Covid-19 is a 61 year-old man who died in China on 9 January 2020, see Baldwin and Weder di Mauro (2020)
} 
February 2020, see Doz et al., 2020). Indeed, facing the immediate absence of vaccines, tests and masks, governments decided, more or less rapidly, to implement lockdown measures with the objective of minimizing health issues at the cost of economic consequences. This unexpected and unusual sequence of supply and demand shocks led to a drop in GDP growth and, among other events, to a rise in financial volatility as measured by the VIX, in global economic policy uncertainty and in pandemic-related uncertainty (see Baker et al., 2020). Yet, at the same time, we observed that the U.S. nominal broad effective exchange rate appreciated by $5 \%$ between January and March 2020, that can be understood as a flight-to-quality move in the presence of increasing global risks.

Relationships between uncertainty measures and exchange rates have been only recently considered in the literature. For example, when taking financial volatility as uncertainty measure, Bussière et al. (2018) show only mixed evidence about the role of the VIX in the determination of exchange rates for a bunch of advanced country currencies. Ismailov and Rossi (2018) show some evidence that the relationship between uncertainty and exchange rates follows a non-linear pattern. Indeed they point out that the Uncovered Interest rate Parity (UIP) condition, a core relationship in international finance relating exchange rate evolution and differential of interest rates, is more likely to hold when uncertainty is low but breaks down during periods of high uncertainty. The argument they put forward is that arbitrage opportunity gains become more uncertain during high uncertainty times, blurring thus the link between exchange rates and interest rate differentials. Recently Ramirez-Rondan and Terrones (2019) also highlight the non-linear dependence between differentials of interest rates and exchange rate depreciation, uncertainty being the transition variable of a multivariate threshold model. As in Ismailov and Rossi (2018), they empirically show that the UIP condition holds when uncertainty is low, while it is not verified in a high uncertainty regime, but they do not provide any clear explanation for this stylized fact.

In this paper, we reconsider the role of uncertainty in exchange rate determination by focusing on two specific periods of time, namely the Brexit episode, starting just after the June 2016 referendum outcome, and the more recent Covid-19 crisis starting in January 2020. Especially, our aim is to provide some new measures of risk assessment for two specific currencies: (i) 
the GBP/EUR exchange rate, one of the bilateral currency that reacted the most due to the close integration between the euro area and the U.K, and (ii) the MXN/USD exchange rate, an emerging country currency (Mexican Peso) vs the currency hegemon (US Dollar). We focus on the Mexican Peso as we wanted to have a look at an emerging country with tight links with the U.S. and a floating currency. This case is also interesting to contrast results from the first analysis on the GBP/EUR as it has been shown that currencies of advanced and emerging countries behave differently (Bansal and Dahlquist, 2000).

Our objective is twofold. First we would like to account for uncertainty in the relationship between exchange rate and interest rate differentials, possibly by allowing for non-linear effect. Second, we would like to compute risk measures around expected exchange rates, for both appreciation and depreciation risks. In this respect, our econometric methodology relies on the extension of the standard Fama regression, that explains exchange rate depreciation by interest rate differentials, by integrating various uncertainty measures as explanatory variables. In order to account for possible asymmetries, we estimate a quantile regression, allowing for a differentiated impact of interest rate differentials and uncertainty, depending on the evolution of the exchange rate. We use this quantile regression to forecast one-month-ahead expectations, as well as the conditional moments of the distribution around the forecasts of exchange rates. Then, in order to quantify risk measures, we fit a generalized Skewed-Student distribution to the one-step-ahead quantiles, in the spirit of Adrian et al. (2019), in order to get the whole conditional density. We see this quantile regression approach as an efficient way to fill our twofold objective.

Empirical results show that this conditional density provides a good way to anticipate appreciation and depreciation risks. Especially, we show that the evolution of risks around the British Pound during the Brexit-related uncertainty period shows a clear shift towards depreciation. In addition, we show that there is a sharp risk of US Dollar appreciation during the Covid-19 crisis as a flight-to-quality move. Our tool can thus be used to monitor in real-time expected appreciation/depreciation risks for any currency.

The rest of the paper is organized in three sections. Section 2 presents the econometric methodology and Section 3 contains our main results for 
both the GDP/EUR and MXN/USD currencies. Last, some conclusions are discussed in Section 4.

\section{Econometric methodology}

\subsection{Fama equation: A quantile regression approach}

There have been many attempts in the econometric literature in order to explain the evolution of exchange rates, and possibly to forecast out-of-sample. A nice review has been done by Rossi (2013), especially focusing on forecasting ability of models. However, one of the most considered relationship in international finance is the one between bilateral exchange rate changes of two countries and the differential of interest between those countries. This relationship, referred to as Uncovered Interest Parity (UIP) condition, is a no-arbitrage condition that can be tested, jointly with rational expectation hypothesis, through a Fama regression (Fama, 1984). In its general form, the Fama regression at a monthly frequency can be written as:

$$
s_{t+h}-s_{t}=\alpha+\beta \times\left(i_{h, t}^{D}-i_{h, t}^{F}\right)+\varepsilon_{t+h},
$$

where $s_{t}$ the logarithm of exchange rate measured as the number of units of domestic currency per one foreign currency, $h$ is a given horizon and $i_{h, t}^{D}$ and $i_{h, t}^{F}$ are respectively the domestic and foreign interest rates for a given maturity $h$. In such a background, $s_{t+h}-s_{t}>0$ refers to an appreciation of the foreign currency (or a depreciation of the domestic currency) over the horizon $h$. Against this background, under the null hypothesis of uncovered interest rate parity and rational expectations we should have $\beta=1$ and the error term $\varepsilon_{t}$ is supposed to be white noise and orthogonal to interest rate differentials.

It turns out that empirical evidence that UIP conditions holds is quite scarce, leading to the well known Fama puzzle. This puzzle relies on the empirical observation that estimated parameters $\beta$ are much lower than the expected value of one, generally very negative. In other words, data tend to show that the high-interest rate currency is likely to appreciate, at odds with theoretical hypothesis. Various explanations have been put forward in the literature pointing out the instability overtime of this relationship (Bussière 
et al., 2018), the sensitivity to the horizon (Chinn and Meredith, 2004) or the non-linearity of the relationship (Baillie and Kilic, 2006). More recently, some papers have shown that the uncertainty is likely to have a non-linear impact on the relationship between changes in exchange rate and interest rate differentials (Ismailov and Rossi, 2018), as high uncertainty is blurring this relationship. In this paper, we extend this line of research by (i) extending a standard Fama regression through the integration of uncertainty measures and (ii) allowing non-linearities into this relationship through quantile regression.

First, we extend the previous Fama equation (1) by integrating the uncertainty generated by the Brexit in the following way:

$$
s_{t+h}-s_{t}=\alpha+\beta \times\left(i_{h, t}^{D}-i_{h, t}^{F}\right)+\gamma \times u n c_{t}+\varepsilon_{t+h},
$$

where $u n c_{t}$ is a measure of uncertainty. There exist various available measures of uncertainty in the literature, such as economic policy uncertainty, forecasts dispersion, financial volatility ... (for a review see Ferrara et al., 2017). However, we think that the Brexit uncertainty is a typical case of uncertainty generated by economic policy and thus we use the Economic Policy Uncertainty (EPU) index for the U.K. developed by Baker et al. (2016). This EPU index is computed by counting some specific keywords in media articles dealing simultaneously with economy, policy and uncertainty (see graph in Annex). As regards the Covid-19 crisis, the choice of an adequate uncertainty measure is not obvious. Baker et al. (2020) have put forward a new measure of Covid-induced uncertainty but this index is like a dummy jumping suddenly in January 2020 to 50, while being close to zero over the remaining of the sample. Our preferred choice is the financial volatility, as measured by the VIX (see graph in Annex), as a proxy for uncertainty. We agree that financial volatility is only a proxy of this pandemic-related uncertainty as other factors are likely to drive the VIX. However, to our view, it makes sense to consider that due to the nature of this unexpected and unusual pandemic shock, the VIX reflects to a large extent the current global uncertainty.

Second, we allow for non-linearities in Equation (2) by estimating parameters within a quantile regression framework, as put forward by Koenker and Bassett (1978). In opposition to the ordinary least squares (OLS) estimation procedure, that minimizes the sum of squared errors, quantile estimation 
is based on the asymmetric minimization of the weighted absolute errors. This methodology presents several advantages. One of them is its capacity to depict, in a better way than OLS, the relationship between two random variables. Instead of estimating only the conditional mean like the OLS, quantile regression enables to estimate all the conditional quantile functions. Furthermore, Koenker and Bassett (1978) argue that in non-Gaussian settings, estimators from a quantile regression are more reliable than the OLS ones. Let's denote $y_{t+h}$ the $h$-month-ahead domestic currency depreciation $\left(s_{t+h}-s_{t}\right)$ and $x_{t}$ the vector of conditioning variables, namely the differential of interest rates and the uncertainty measure. The quantile regression estimator for a given quantile $\tau$ is given as follows:

$$
\begin{array}{r}
\hat{\beta}_{\tau}=\arg \min _{\beta_{\tau}} \sum_{t=1}^{T-1}\left(\tau . \mathbb{1}_{\left(y_{t+h} \geq x_{t} \beta\right)}\left|y_{t+h}-x_{t} \beta_{\tau}\right|+\right. \\
\left.(1-\tau) . \mathbb{1}_{\left(y_{t+h}<x_{t} \beta\right)}\left|y_{t+h}-x_{t} \beta_{\tau}\right|\right),
\end{array}
$$

where $\mathbb{1}_{(.)}$the indicator function. Koenker and Bassett (1978) demonstrate

that the predicted value $\hat{Q}_{y_{t+h} \mid x_{t}}\left(\tau \mid x_{t}\right)=x_{t} \hat{\beta}_{\tau}$ is a consistent linear estimator of the conditional quantile function of $y_{t+h}$.

\subsection{Risk measurement}

Based on previous estimates of the quantiles of the distribution of expected values $\hat{y}_{t+h}$, we are now able to estimate some risk measures of future evolution of the bilateral exchange rate. However, estimated quantiles do not ensure a continuous distribution function, it may be that some quantiles are badly estimated, if for example only few data points belong to this specific quantile. In this respect, we use the methodology pointed out in a recent paper by Adrian et al. (2019), in which they try to assess risks around future GDP growth, and we fit a generalized Skewed-Student distribution based on the estimated quantiles. Finally, we will use the estimated conditional distributions to measure the associated risks, within the expected shortfall/longrise framework.

The conditional quantiles $\hat{Q}_{y_{t+h} \mid x_{t}}\left(\tau \mid x_{t}\right)$ obtained from the quantile regressions can be used to fit distributions. In a key paper in the field, Koenker 
(2005) provides a formula to transform the estimated conditional quantile functions into conditional densities. Gaglianone and Lima (2012) build on this framework and fit an Epanechnikov Kernel to smooth the inverse $c d f$ obtained from the quantile regressions. Similarly, Korobilis (2017) uses this methodology in a panel framework. More recently, Adrian et al. (2019) fit a Skewed-Student distribution to estimate the conditional densities of the US economic growth. We follow Adrian et al. (2019) and fit a Skewed-Student distribution to estimate the conditional densities of the expected currency. The probability density function of the generalized Skewed-Student distribution is given by:

$$
f(y ; \mu, \sigma, \alpha, \nu)=\frac{2}{\sigma} t\left(\frac{y-\mu}{\sigma} ; \nu\right) T\left(\alpha \frac{y-\mu}{\sigma} \sqrt{\frac{\nu+1}{\nu+\left(\frac{y-\mu}{\sigma}\right)^{2}}} ; \nu+1\right),
$$

where $\mu$ is a location parameter, $\sigma$ a scale parameter, $\nu$ a fatness parameter and $\alpha$ a shape parameter. $t($.$) and T($.$) are respectively the probability den-$ sity function $(p d f)$ and the cumulative density function $(c d f)$ of the Student t-distribution. The quantile matching approach consists in estimating the four parameters of the generalized Skewed-Student distribution by minimizing the squared distance between the estimated conditional quantile functions and the inverse $c d f$ of the generalized Skewed-Student distribution. Since we estimate four parameters, we run the quantile matching for four different percent quantiles: $5 \%, 25 \%, 75 \%$ and $95 \%$. In other words, we choose the four parameters to match the four different percentiles mentioned above. The quantile matching approach boils down to solve the following minimization:

$$
\begin{aligned}
& \left\{\hat{\mu}_{t+h}, \hat{\sigma}_{t+h}, \hat{\alpha}_{t+h}, \hat{\nu}_{t+h}\right\}= \\
& \underset{(\mu, \sigma, \alpha, \nu)}{\arg \min } \sum_{\tau}\left(\hat{Q}_{y_{t+h} \mid x_{t}}\left(\tau \mid x_{t}\right)-F^{-1}(\tau ; \mu, \sigma, \alpha, \nu)\right)^{2},
\end{aligned}
$$

where $F^{-1}($.$) is the inverse cumulative skewed t-distribution. As a result, we$ get the four estimated parameters of the Skewed-Student distribution and we denote $\hat{f}($.$) the estimated Skewed-Student density and \hat{F}^{-1}($.$) its inverted$ estimated $c d f$.

Starting from this estimated density function $\hat{f}($.$) , we can now compute some$ risk measures to assess depreciation/appreciation risk $h$-step-ahead of the 
British Pound versus the Euro. A standard risk measure in empirical finance is the Value-at-Risk ( VaR). It measures the maximum loss of an asset over a given time horizon and at a defined confidence level. However, it is now well known that the VaR presents some drawbacks among them its inability to account for extreme losses. In this respect, the Expected Shortfall (ES hereafter) is presented now as a better risk measure than the VaR and is defined as the total probability mass that the conditional density assigns to the left tail. In other words, it measures the average loss beyond the VaR. The ES is given by:

$$
E S_{t+h}=\frac{1}{\pi} \int_{0}^{\pi} \hat{F}_{y_{t+h} \mid x_{t}}^{-1}\left(\tau \mid x_{t}\right) \mathrm{d} \tau
$$

where $\pi$ is the risk level and $\hat{F}_{y_{t+h} \mid x_{t}}^{-1}\left(\tau \mid x_{t}\right)$, the estimated conditional cumulative Skewed-Student distribution. As we are also interested in the appreciation risk of the British Pound, we consider the symmetric of the ES, that is the Expected Longrise (EL hereafter) which is the upper tail counterpart of the ES. The EL can be expressed as follows:

$$
E L_{t+h}=\frac{1}{\pi} \int_{1-\pi}^{1} \hat{F}_{y_{t+h} \mid x_{t}}^{-1}\left(\tau \mid x_{t}\right) \mathrm{d} \tau
$$

In the subsequent empirical part of this paper, we will consider a risk level of $5 \%$ for both ES and EL.

\section{Empirical results}

In this section, we present empirical results of the previously introduced approach to measure and forecast in the short term appreciation and depreciation risks. The first application deals with the Brexit-related uncertainty period and focuses on the risks around the British Pound vs the Euro, while the second application assesses risks around the US Dollar vs the Mexican Peso during the Covid-19 crisis. In this paper we focus on the short-term horizon of $h=1$ month as the literature is pointing out that the main deviation to UIP condition is for short-term horizons (Chinn and Meredith, 2004). 


\subsection{GBP/EUR during the Brexit}

In this application, we collect monthly data for the GBP/EUR exchange rate (i.e. the value of one British Pound expressed in Euros, see monthly log-changes in Figure 6), interest rate differentials between the euro area and the United Kingdom (see Figure 7) and the Economic Policy Uncertainty index (see Figure 8) as computed by Baker et al. (2016). All figures are presented in the Annex. The data spans from January 2000 to December 2018.

Let's start by presenting the results of the quantile regression stemming from the estimation of Equation (2), by lagging the uncertainty measure by one month. Figure 1 presents the estimated parameters stemming from the quantile regression, for various quantiles, as well as confidence intervals estimated by Bootstrap with a $95 \%$ confidence level $^{2}$. The procedure considers 20 different quantiles $\tau$, from $\tau=0.05, \ldots 0.95$. The estimated parameter of the Fama coefficient $\beta$ switches from negative (for the left tail) to positive (for the right tail). In other words, in periods of strong depreciation of the British Pound (or strong appreciation of the Euro), the Fama coefficient tends to be negative (about -10 for quantiles below 0.2). Against this background, a rise of the interest rate in the euro area, everything else equal, induces an appreciation (a depreciation) of the Euro (the British Pound). This result reflects what has been called the Fama puzzle in the empirical literature. In opposition, in times of high appreciation of the British Pound (or high depreciation of the Euro), the Fama coefficient tends to be positive. It turns out that starting from the quantile $\tau=0.6$, the coefficient is significantly positive, close to +10 . This means that in times of strong depreciation of the Euro, a monetary policy tightening from the ECB leads to a further depreciation of the Euro (in opposition to common wisdom about the impact of monetary policy on exchange rate). Those results related to the right tail of the distribution reflect the new Fama puzzle of Bussière et al. (2018).

Compared to the OLS estimator (horizontal red line in Figure 1), we see that the Fama coefficient tends to show significant evidence of non-linearity depending on the values of the exchange rate. The OLS estimator is equal to $\hat{\beta}^{O L S}=3.73$, that is much higher than its expected value of one, according to the UIP and rational expectations condition. Thus it means that an increase

\footnotetext{
${ }^{2}$ We use the $\mathrm{R}$ package quantreg for computations
} 
Figure 1: Quantile regression estimators
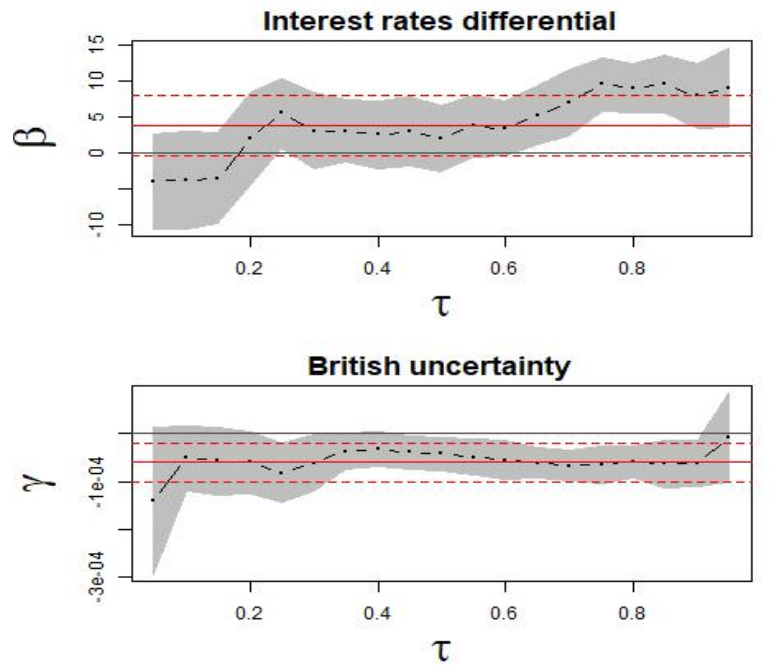

Note: The dotted black line represents the estimated quantile regression estimator. The shaded area is the confidence interval. The solid red line is the OLS estimator

in the euro area interest rate tends to depreciate the Euro the month after.

The estimated parameter $\hat{\gamma}$ for the British uncertainty remains negative for any quantile, close to the OLS estimate $\hat{\gamma}^{O L S}=-0.00006$ that is significantly negative. It means that a rise in UK policy uncertainty always leads to a depreciation of the British Pound (or an appreciation of the Euro). In the left tail of the distribution (when the British Pound is rapidly depreciating), the negative impact of the uncertainty is a bit stronger. Overall, this parameter doesn't show a strong non-linear pattern, namely uncertainty seems to always play negatively, whatever the exchange rate values.

Let's now focus on the conditional distribution $\hat{f}($.$) of the 1-month-ahead$ forecasts of the GBP/EUR exchange rate. Using estimated quantile regression estimators we draw the Skewed-Student conditional densities for any date $t$ from Equation (4). Time-varying conditional distributions are presented in Figure 2. We observe that the conditional densities are somewhat symmetric before 2016. Then at time of the referendum result, we note a clear shift to the left of the distribution, indicating an increase in the forecast 
Figure 2: Conditional distribution of EUR/GBP exchange rate

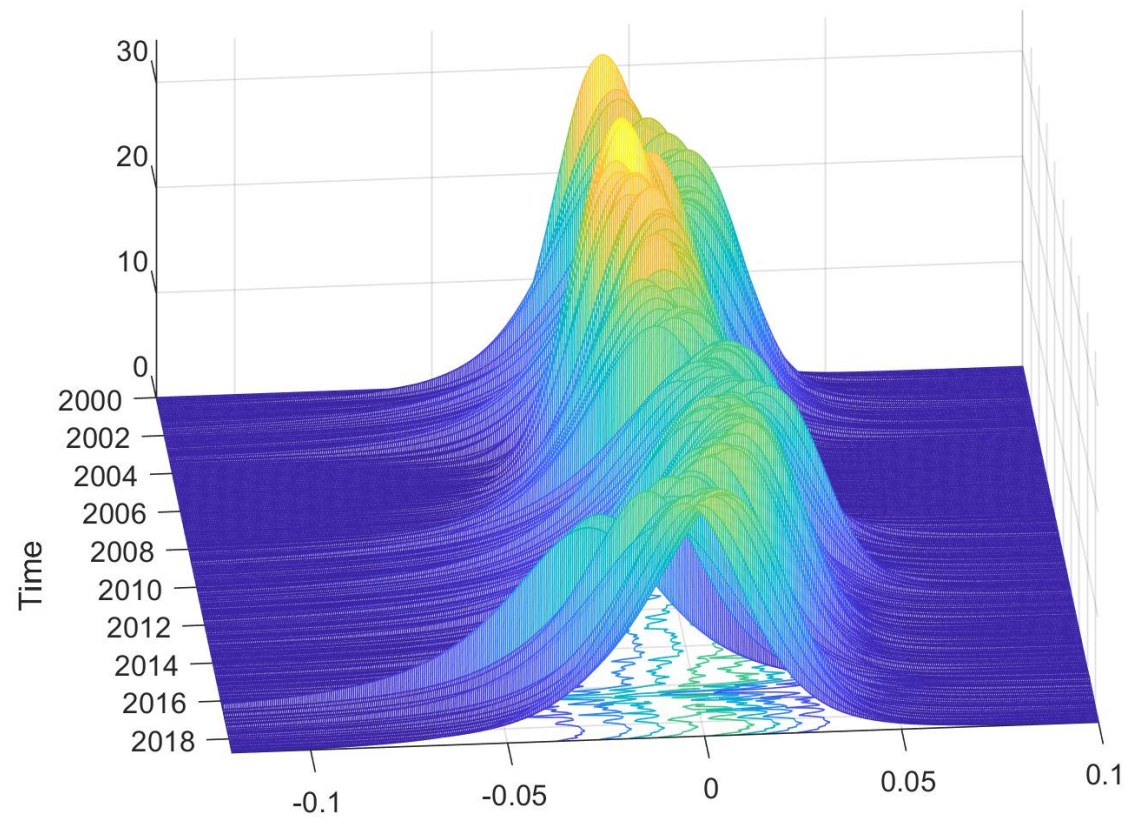

Note: Negative values correspond to GBP depreciation and positive values to EUR depreciation

depreciation risk of the sterling, in line with the jump in the economic policy uncertainty. Just after the surprising outcome of the referendum, the distribution became less skewed to the left, but depreciation risks stayed much higher and the variance larger.

The last part of our methodology is the computation of the risk measures: the expected shortfall/longrise (ES and EL) as given by Equation (6) and Equation (7). Figure 3 highlights an asymmetric pattern between depreciation and appreciation risks. Indeed, the depreciation risk of the British Pound is more volatile and larger than the appreciation risk. If we focus on the Brexit period, we notice a sharp drop in the depreciation risk. It decreases from -0.08 in May 2016 to -0.15 in June 2016 and reaches -0.17 in July 2016, just after the Brexit vote. To sum up, the uncertainty around Brexit leads to a significant increase of the 1-month-ahead depreciation risk 
Figure 3: Depreciation and appreciation risks for the British Pound

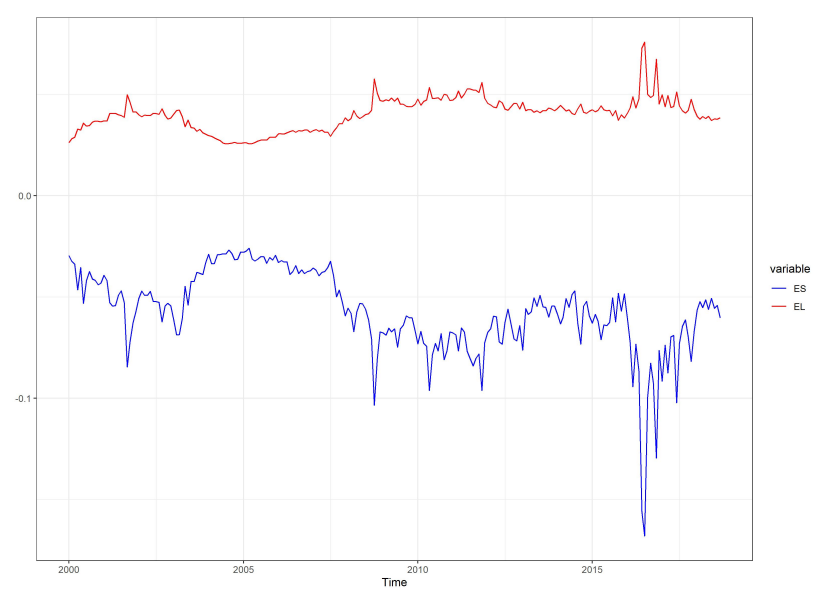

Note: Blue line is the Expected Shortfall and red line is the Expected Longrise. A decrease in the ES corresponds to a GBP depreciation risk, while an increase in the EL corresponds to a GBP appreciation risk

of the British Pound.

\subsection{MXN/USD during the Covid-19 crisis}

In this application, we collect monthly data for the MXN/USD exchange rate (see monthly log-changes in Figure 9), 1-month interest rate differentials between Mexico and the U.S. (see Figure 10) and the VIX index (see Figure 11). All figures are presented in the Annex. The data spans from January 2003 to April 2020, covering thus the beginning of the Covid-19 crisis.

Let's start by presenting the results of the quantile regression stemming from the estimation of Equation (2). Figure 4 presents the estimated parameters stemming from the quantile regression, for various quantiles, as well as confidence intervals estimated by Bootstrap, with a $95 \%$ confidence level. The procedure considers 20 different quantiles $\tau$, from $\tau=0.05, \ldots 0.95$. The OLS estimated parameter of the Fama coefficient $\beta$ is negative, $\hat{\beta}^{O L S}=-2.2$ in line with the standard Fama puzzle. However when considering the quantile estimated parameters, they are positive for lowest quantiles and are slightly 
Figure 4: Quantile regression estimators for MXN/USD
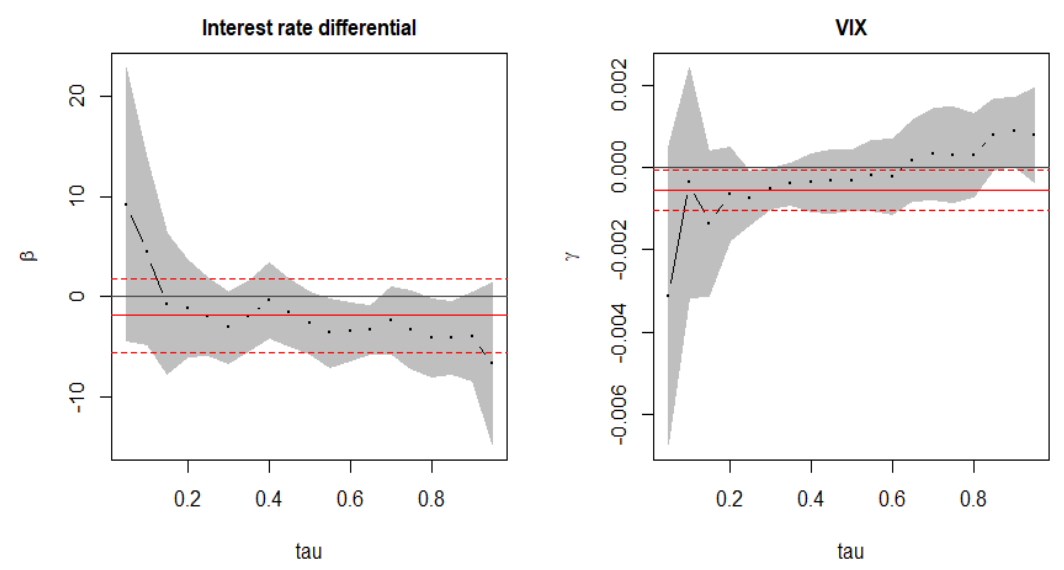

Note: The dotted black line represents the estimated quantile regression estimator. The shaded area is the confidence interval at the $95 \%$ level. The solid red line is the OLS estimator

negatively significant for higher quantiles. In other words, in periods of strong depreciation of the Peso (or strong appreciation of the US Dollar), the Fama coefficient tends to be highly positive, though non-significant. Against this background, a cut in US interest rates, everything else equal, induces a depreciation (an appreciation) of the Peso (the US Dollar) one month after. This stylized fact tends to reflect the perception of the US Dollar as a safe haven currency. Even when the US economy lies in the low phase of the cycle, the US Dollar tends to appreciate vs the Mexican Peso.

An interesting result is about the role of uncertainty. Overall, the OLS estimate is slightly significantly negative, $\hat{\gamma}^{O L S}=-0.00054$, meaning that on average a positive shock to the VIX translates to into a USD appreciation, in a flight-to-quality move. However, the estimated uncertainty coefficient $\gamma$ shows a high degree of non-linearity and tends to increase with the quantiles. It turns out that for lowest quantiles, i.e. when the Peso depreciates (or the US Dollar appreciates), the VIX is playing negatively even though the confidence interval is large. It means that during US Dollar appreciation periods, a spike in financial volatility tends to appreciate even more the US Dollar. In opposition, for highest quantiles the coefficient $\gamma$ is slightly significantly 
Figure 5: Depreciation and appreciation risks for the Mexican Peso vs the US Dollar

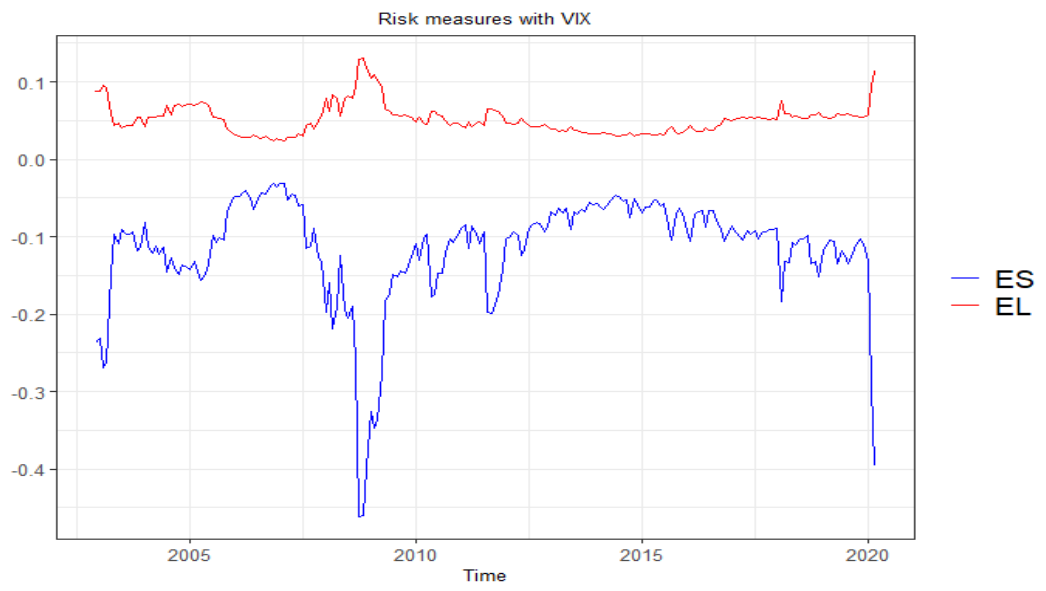

Note: Blue line is the Expected Shortfall and red line is the Expected Longrise. $A$ decrease in the ES corresponds to a Mexican Peso depreciation risk, while an increase in the EL corresponds to a Mexican Peso appreciation risk

positive, meaning that during Peso appreciation phases, a jump in the financial volatility leads to a continuation of this appreciation phase.

Let's focus now on the conditional distribution $\hat{f}($.$) of the 1-step-ahead$ forecasts of the MXN/USD exchange rate. Using estimated quantiles, we estimate the Skewed-Student conditional densities for any date $t$ from equation (4). Time-varying conditional 1-step-ahead distributions are presented in Figure 12 in the Annex. First, we observe a recent shift to the left in the conditional distribution over the last points for beginning of 2020. From those results we derive the ES and EL risk measures as defined by equations (6) and (7). Figure 5 presents the ES and EL risk measures, highlighting a clear asymmetry between depreciation and appreciation risks. Indeed, each time the VIX rises we have a contemporaneous large drop in the ES, meaning higher expected Mexican Peso depreciation risks. The observed drops in the ES are mirrored by much smaller spikes in the EL reflecting the asymmetric behaviour of the conditional distribution. In the wake of the Covid-19 crisis, the ES falls to levels close to what we observed during the Global Financial Crisis. This reflects the overall uncertainty on financial markets 
during this crisis, leading as usual to a U.S. Dollar appreciation, specially versus emerging economies. This expected depreciation risk on the Peso is likely to put additional macroeconomic risks on Mexico in upcoming months.

\section{Conclusion}

In this paper, we put forward an innovative approach based on quantile regression in order to assess 1-month-ahead appreciation and depreciation risks for a given currency, conditionally to uncertainty. First, we apply this methodology to anticipate the Sterling depreciation risk with respect to the Euro, during the Brexit-related uncertainty period, by augmenting the standard Fama regression with an economic policy uncertainty measure. We point out that depreciation risks for the British Pound largely increased by comparison with appreciation risks, reflecting low expectations of future UK potential growth. In a second application, we focus on the Covid-19 crisis to underline that this crisis generated an increase in global uncertainty as measured by the VIX, leading in turn to a flight-to-quality phenomenon that is visible in the increasing appreciation risk of the US Dollar vs the Mexican Peso. Overall, we show that our approach enables to anticipate short-term risks around exchange rates during periods of high uncertainty. 


\section{References}

[1] Adrian, T. and Boyarchenko, N. and Giannone, D. (2019). "Vulnerable growth." American Economic Review, 109(4), 1263-1289.

[2] Baillie, R. and Kilic, R. (2006). "Do asymmetric and nonlinear adjustments explain the forward premium anomaly?". Journal of International Money and Finance, 25, 1, 22-47.

[3] Baker, S. R. and Bloom, N. and Davis, S. J. (2016). "Measuring Economic Policy Uncertainty." The Quarterly Journal of Economics, 131(4), $1593-1636$.

[4] Baker, S. R. and Bloom, N. and Davis, S. and Terry, S. (2020). "Covidinduced economic uncertainty." NBER Working Paper No. 26983.

[5] Baldwin, R. and Weder di Mauro, B. (2020). Mitigating the COVID Economic Crisis: Act Fast and Do Whatever It Takes, VoxEU.org Book, CEPR.

[6] Bansal, F. and Dahlquist, M. (2000). "The forward premium puzzle: different tales from developed and emerging economies." Journal of International Economics, 51, 115-144.

[7] Bloom, N. (2009). " The Impact of Uncertainty Shocks." Econometrica, $77(3), 623-685$.

[8] Bloom, N. and Bunn, P. and Chen, S. and Mizen, P. and Smietanka, P. and Thwaites, G. (2019). "The Impact of Brexit on UK Firms." NBER Working Paper 26218.

[9] Born, B. and Mueller, G. and Schularick, M. and Sedlacek, P. (2019). "The Costs of Economic Nationalism: Evidence from the Brexit Experiment." The Economic Journal, 129(623), 2722-2744 .

[10] Bussière, M. and Chinn, M. and Ferrara, L. and Heipertz, J. (2018). "The new Fama puzzle." NBER Working Paper 24342.

[11] Chinn, M. and Meredith, G. (2004). "Monetary policy and long horizon uncovered interest parity". IMF Staff Papers, 51, 3, 409-430. 
[12] Dhingra, S. and Ottaviano, G. I. P. and Sampson, T. and Reenen, J. V. (2016). "The consequences of Brexit for UK trade and living standards", LSE Research Online Documents on Economics 66144.

[13] Doz, C. and L. Ferrara and P.-A. Pionnier (2020). "Business cycle dynamics: An extended Markov-Switching Dynamic Factor Model", Econbrowser Blog, April 2020.

[14] Fama, E. (1984). "Forward and spot exchange rates". Journal of Monetary Economics, 14, 319-338.

[15] Ferrara, L. and S. L'Huissier and F. Tripier (2017). "Uncertainty fluctuations: Measures, effects and macroeconomic policy challenges", CEPII Policy Brief No. 20, December 2017.

[16] Gaglianone, W. P. and Lima, L. (2012). "Constructing density forecasts from quantile regressions." Journal of Money, Credit and Banking, 44, $1589-1607$.

[17] Gourinchas, P.-0. and Hale, G. (2017). "Whiter the Pound". Economic Letter, Federal Reserve Bank of San Francisco, No. 2017-11.

[18] Hassan, T. A. and Hollander, S. and van Lent, L. and Tahoun, A. (2019)." The global impact of Brexit uncertainty.", NBER Working Paper 26609 .

[19] Ismailov, A. and Rossi, B. (2018). "Uncertainty and deviations from uncovered interest rate parity." Journal of International Money and Finance, $88,242-259$.

[20] Koenker, R. and Bassett, G. (1978). "Regression Quantiles." Econometrica, 46(1), 33-50.

[21] Koenker, R. (2005). "Quantile Regression." Cambridge: Cambridge University Press.

[22] Korobilis, D. (2017). "Quantile regression forecasts of inflation under model uncertainty." International Journal of Forecasting, 33, 11-20.

[23] Knight, F. (1921). "Risk, uncertainty and profits", Boston, MA : Hart, Schaffner and Marx; Houghton Mifflin Company. 
[24] Ramirez-Rondan, N.R. and Terrones, M. E. (2019). "Uncertainty and the Uncovered Interest Parity Condition: How Are They Related?" MPRA Paper 97524.

[25] Rossi, B. (2013). "Exchange rate predictability." Journal of Economic Literature, 51, 4, 1063-1119. 


\section{APPENDIX}

Figure 6: Monthly log-changes in GBP/EUR exchange rate

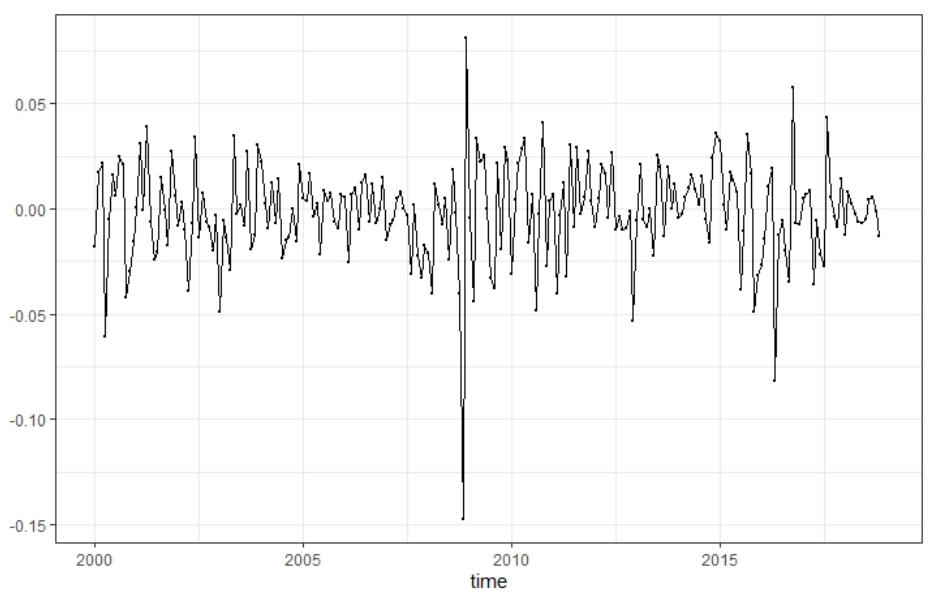

Figure 7: Interest rates differential between EUR and GBP

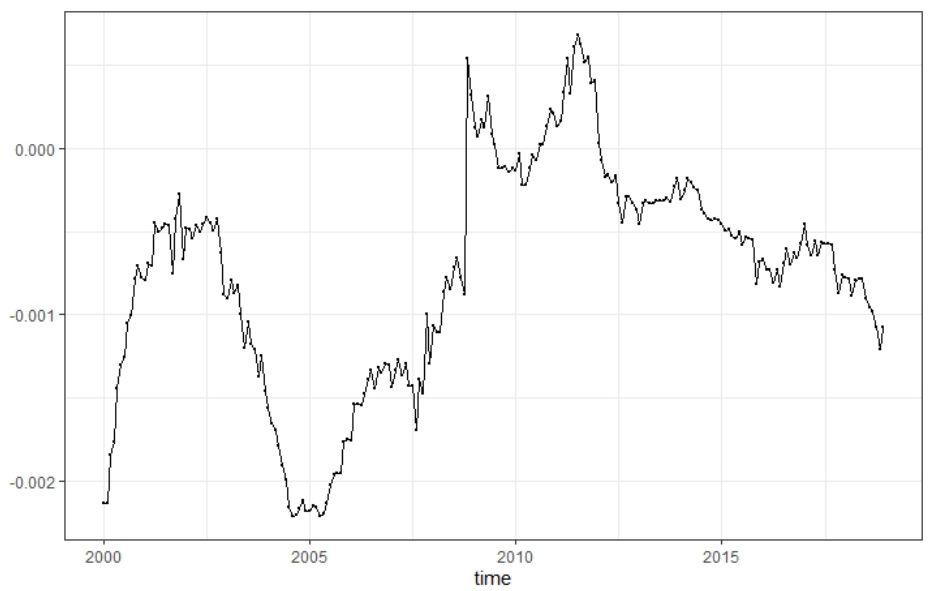

Note: Difference between 1-month interest rates on euro area and British government bonds 
Figure 8: Economic policy uncertainty for the UK

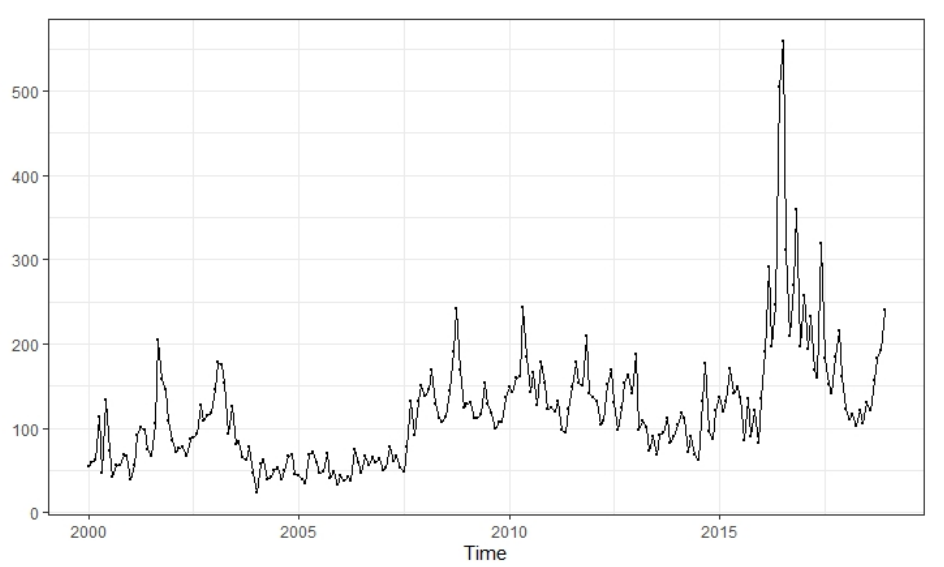

Note: Economic Policy Uncertainty index from 2000 to 2018 as computed by Baker et al. (2016), available on the web site www.policyuncertainty.com

Figure 9: Monthly log-changes of the MXN/USD exchange rate

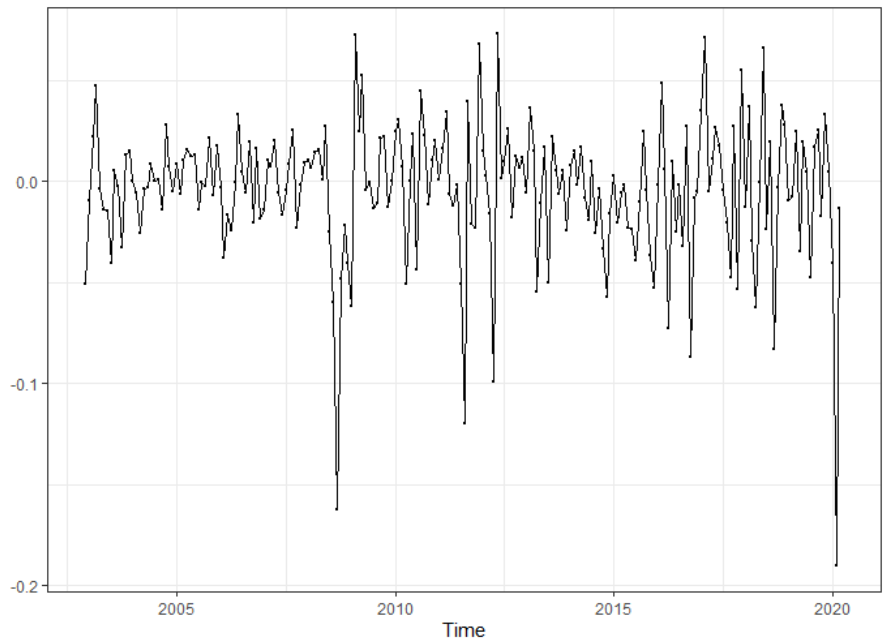

Note: A negative growth rate indicates a depreciation of the Mexican Peso, and conversely 
Figure 10: Interest rate differential between Mexico and the U.S.

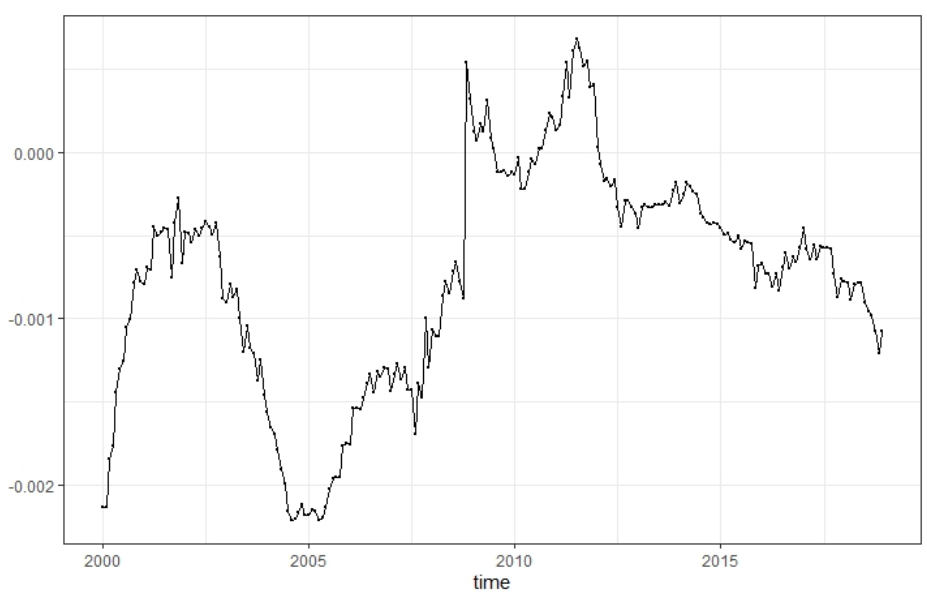

Note: Difference between 1-month interest rates of Mexican and U.S. government bonds

Figure 11: VIX index

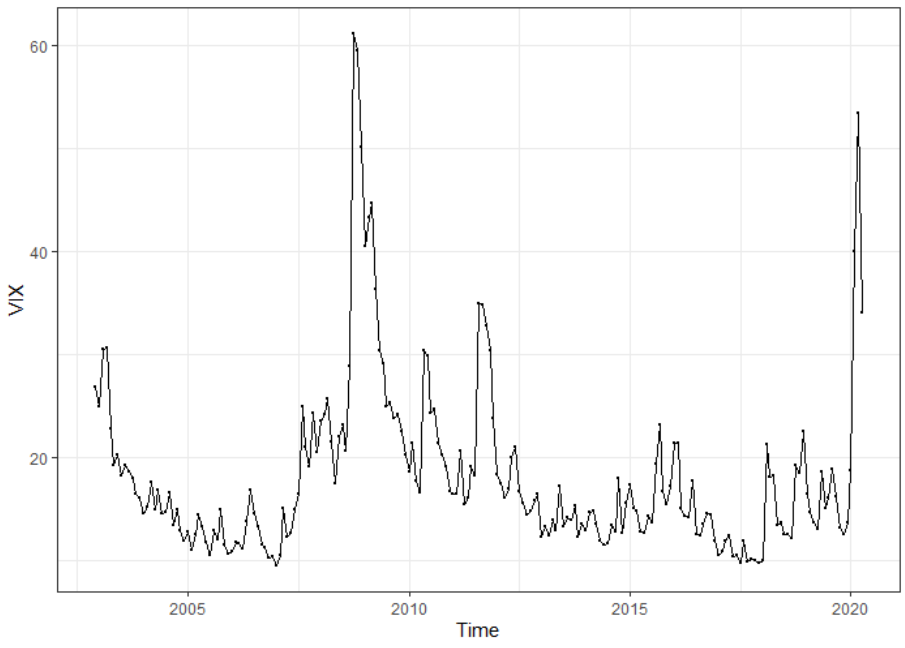

Note: VIX index from 2003 to 2020 (March) 
Figure 12: Conditional distribution of MXN/USD exchange rate

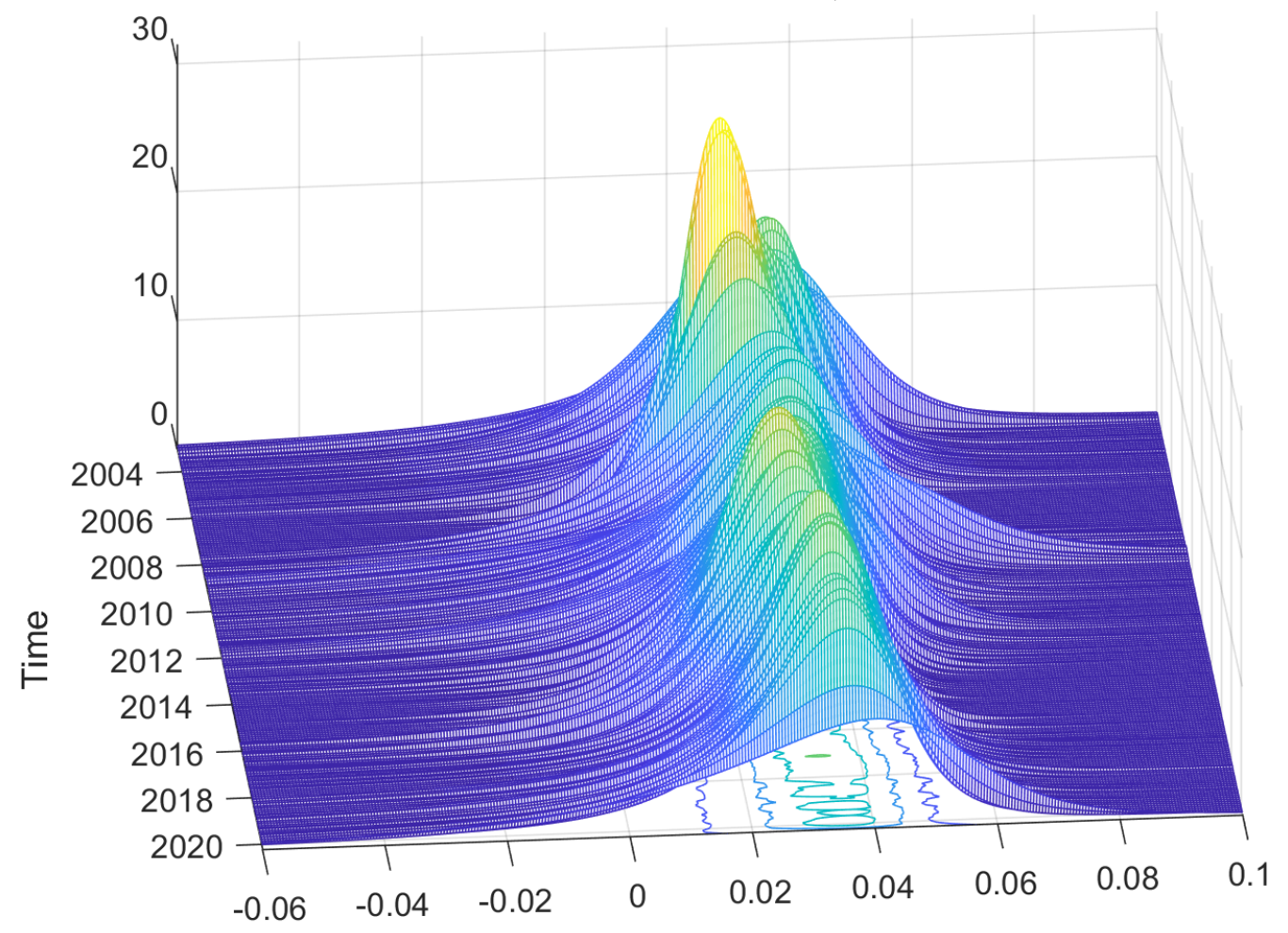

Note: Negative values correspond to MXN depreciation and positive values to USD depreciation 